\title{
Site selection for a countrywide temporary network in Austria: noise analysis and preliminary performance
}

\author{
F. Fuchs, P. Kolínský, G. Gröschl, M.-T. Apoloner, E. Qorbani, F. Schneider, and G. Bokelmann \\ Department of Meteorology and Geophysics, University of Vienna, Althanstraße 14, UZA 2, 1090 Vienna, Austria \\ Correspondence to: F. Fuchs (florian.fuchs@univie.ac.at)
}

Received: 30 July 2015 - Revised: 5 October 2015 - Accepted: 9 October 2015 - Published: 16 October 2015

\begin{abstract}
Site selection is a crucial part of the work flow for installing seismic stations. Here, we report the preparations for a countrywide temporary seismic network in Austria. We describe the specific requirements for a multi-purpose seismic array with $40 \mathrm{~km}$ station spacing that will be operative approximately three years. Reftek 15160 s sensors and Reftek 130/130S digitizers form the core instrumentation of our seismic stations which are mostly installed inside abandoned or occasionally used basements or cellars. We present probabilistic power spectral density analysis to assess noise conditions at selected sites and show exemplary seismic events that were recorded by the preliminary network by the end of July 2015 .
\end{abstract}

\section{Introduction}

Site selection is a crucial part of the work flow for installing seismic stations. Detailed instructions on site scouting and preparations are formulated e.g. by Trnkoczy et al. (2012), yet the specific requirements for each seismic station depend on the scientific aim. Obviously, permanent broadband seismic stations require more thorough and cost-intensive site preparations than temporary or short period stations. Temporary station networks are often designed for a balance between data quality and project budget and thus can be realized in many ways. Installations for detection of local seismicity will e.g. aim to minimize high frequency anthropogenic noise and thus try to avoid deployments near populated and especially industrial areas. In turn, experiments that focus on long period seismic data suffer less from anthropogenic noise, but the broadband sensors require proper thermal insulation and shielding from atmospheric pressure fluctuations (Bormann and Wielandt, 2012; Forbinger, 2012).
Consequently, the preferred type of seismic site often depends on experiment duration, scientific target and available budget. In this manuscript, we describe our preparations for a multi-purpose countrywide network of broadband stations in Austria, for a temporary deployment of approximately three years.

\section{Scientific goals, network layout and station design}

\subsection{Scientific goals}

The sites we describe in this manuscript are testing sites for the Austrian part of the international AlpArray seismic network (Kissling et al., 2014). AlpArray is a unique European transnational research initiative in which 43 research institutes from 15 countries join their expertise to advance our knowledge about the structure and evolution of the lithosphere beneath the entire Alpine area. AlpArray will shed light on the detailed geological structure and geodynamical evolution of the Alps to answer outstanding questions e.g. on slab geometry and subduction polarity under the Eastern Alps. While the primary scope of AlpArray is fundamental research the unique dataset will also improve our knowledge about near-surface geologic structures and help to assess the seismic hazard in the Alpine area. The scientific goals of the AlpArray project are manifold and among others include e.g. Alpine geodynamics, crustal and mantle imaging, seismic anisotropy, as well as regional and local seismic activity. Hence, temporary seismic stations installed in the framework of AlpArray should be multi-purpose stations that perform reasonably well both for frequencies above and below the microseism peaks. 


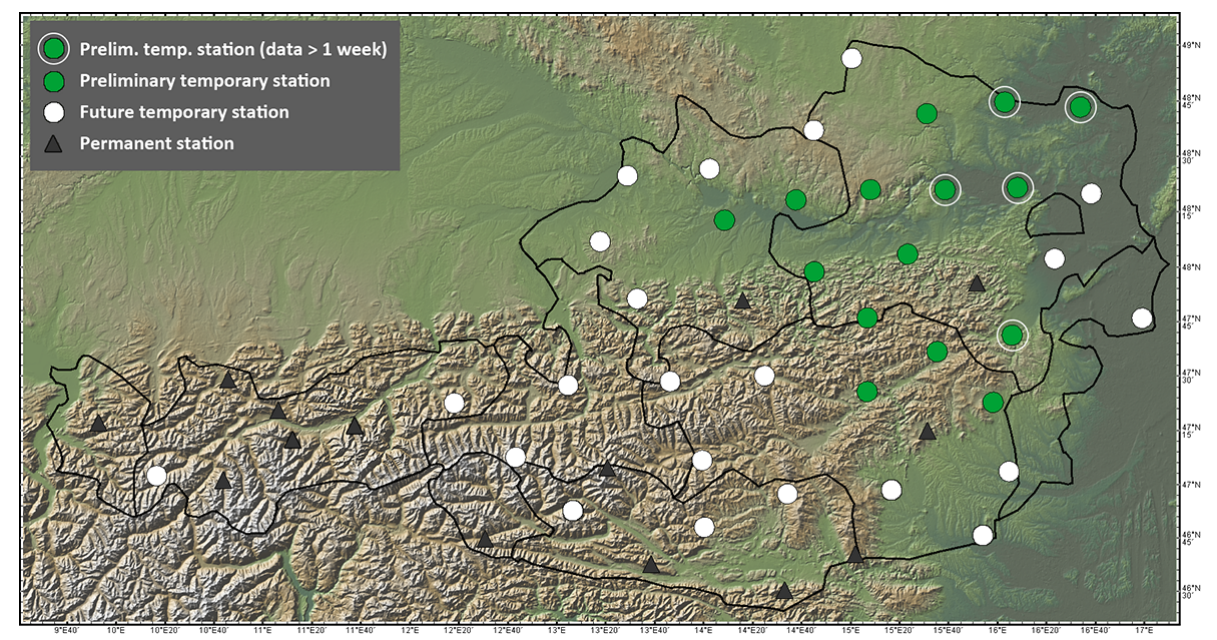

Figure 1. Prospective layout for the countrywide temporary network in Austria. Black Triangles mark existing permanent stations. White dots mark future temporary broadband stations and green dots mark existing preliminary testing stations. The five stations discussed in detail in Section 3 are marked with an additional circle.
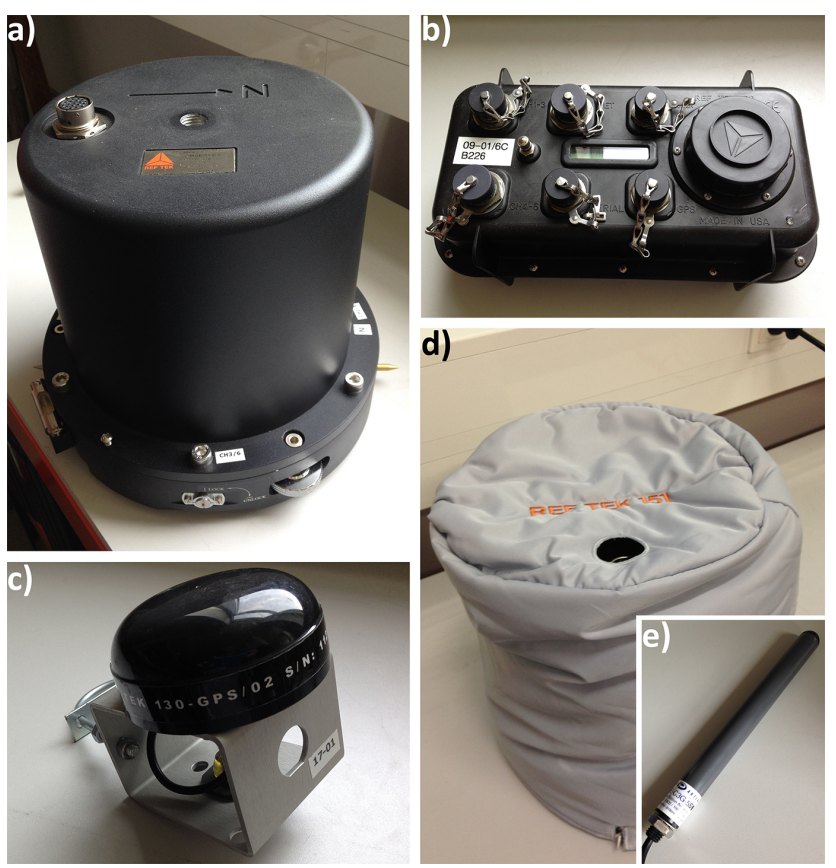

Figure 2. Equipment used for the installations described in this manuscript. (a) Reftek 15160 s sensor, (b) Reftek 130/130S digitizer, (c) Reftek 130 GPS antenna, (d) textile thermal insulation cover for the sensor, (e) mobile network antenna.

\subsection{Network layout}

The AlpArray temporary seismic network is designed to complement existing permanent seismic stations. In Austria the Austrian Central Institute for Meteorology and Geodynamics operates 15 permanent stations (Fig. 1). The additional temporary seismic stations densify this network to achieve a uniform coverage with approximately $40 \mathrm{~km}$ interstation spacing. Central coordinates for all temporary AlpArray stations were computed to obtain homogeneous coverage throughout the entire array and all stations must be installed within a $3 \mathrm{~km}$ radius around the central coordinates. This constraint usually limits the choice of potential installation sites.

\subsection{Station design}

One seismic station comprises the following components (Fig. 2): a $60 \mathrm{~s}$ broadband sensor Reftek 151 "Observer" together with a Reftek 130 or Reftek 130S 24 bit digitizer with $>136 \mathrm{~dB}$ dynamic range (at $100 \mathrm{~Hz}$ sampling rate), a continuous mode Reftek 130 GPS, a Digi WAN 3G mobile router for telemetry and a $100 \mathrm{Ah}$ battery. For stations not connected to the power grid $100 \mathrm{~W}$ solar panels charge the supply battery. Especially in Alpine regions snow coverage during winter may, however, prevent power supply through solar panels. In this case fuel cells can act as backup power source when the batteries are drained below a given threshold. For a temporary deployment of approximately three years, our specific requirements for seismic sites inside the $3 \mathrm{~km}$ radius were the following:

- Seismic noise: Average noise levels should be $20 \mathrm{~dB}$ lower than the New High Noise Model (NHNM) (Peterson, 1993) on all components within the $1-20 \mathrm{~Hz}$ frequency range. For long periods (30-200 s range) average noise levels on the vertical component should be $20 \mathrm{~dB}$ lower than the NHNM while on horizontal components noise levels should only be $10 \mathrm{~dB}$ less than the NHNM. This accounts for the strong sensitivity of horizontal components to e.g. long-period surface tilt from atmospheric pressure fluctuations. Consequently, 

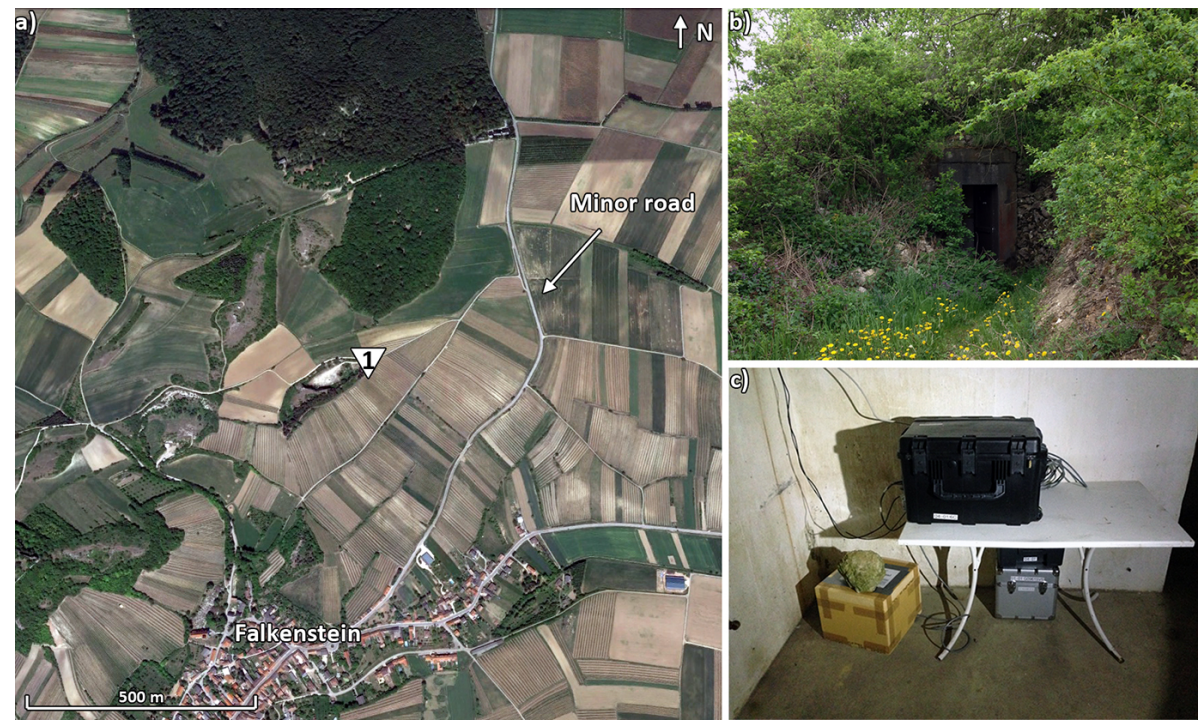

Figure 3. Station 01: (a) aerial view of the surroundings with potential noise sources highlighted, (b) outside view of installation, (c) inside view of installation.
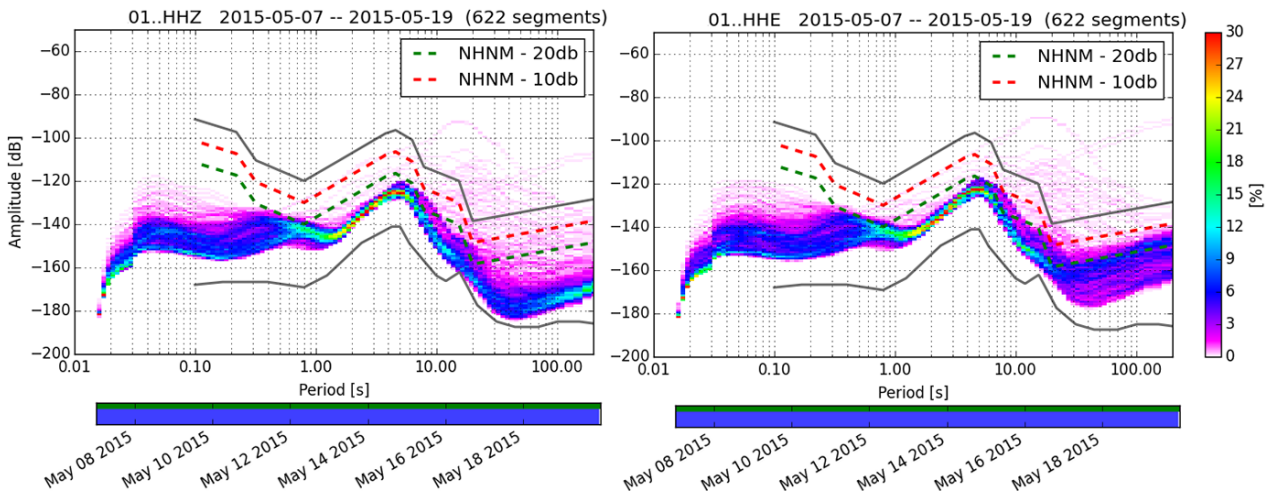

Figure 4. Probabilistic power spectral density of 12 days in spring 2015 of data for Station 01. Left panel: vertical component (HHZ), right panel: horizontal E-W component (HHE).

for near-surface stations, noise on horizontal components is usually stronger than on the vertical. Avoiding long-period noise on horizontal components requires advanced site preparation (Forbinger, 2012) which is usually out of scope for temporary deployments.

- Accessibility and safety: All sites should be accessible by car and safe in terms of theft or flood risk and all parts of the station shall not be exposed to any risk of potential damage. Additionally, the terms and conditions of the instrument insurance require the seismic stations to be indoors in spaces that can be locked. The surroundings of the site should not significantly change over the course of three years.

- Power supply: Most parts of Austria experience snow fall during winter and thus for many sites power supply through solar panels cannot be guaranteed. Hence, we prefer sites were power supply from the regular $50 \mathrm{~Hz} / 230 \mathrm{~V}$ power grid is possible.

- Connectivity: For monitoring purposes all seismic stations should send live data using the mobile network. Minimum requirement is sufficient signal strength and stability to transmit state-of-health data, while preferably continuous $100 \mathrm{~Hz}$ waveform should be transmitted. For our instrumentation and $100 \mathrm{~Hz}$ waveform data in STEIM1 compression format, the amount of data to transmit is approximately 30 Megabytes day $^{-1}$ for seismically quiet sites and 50 Megabytes day $^{-1}$ for noisy sites. Thus, for $100 \mathrm{~Hz}$ real-time waveform streams a mobile bandwidth of $5-10 \mathrm{kbits} \mathrm{s}^{-1}$ should be sufficient, which can even be achieved in GSM networks. In fact, stability of the mobile connection is more important than bandwidth. 


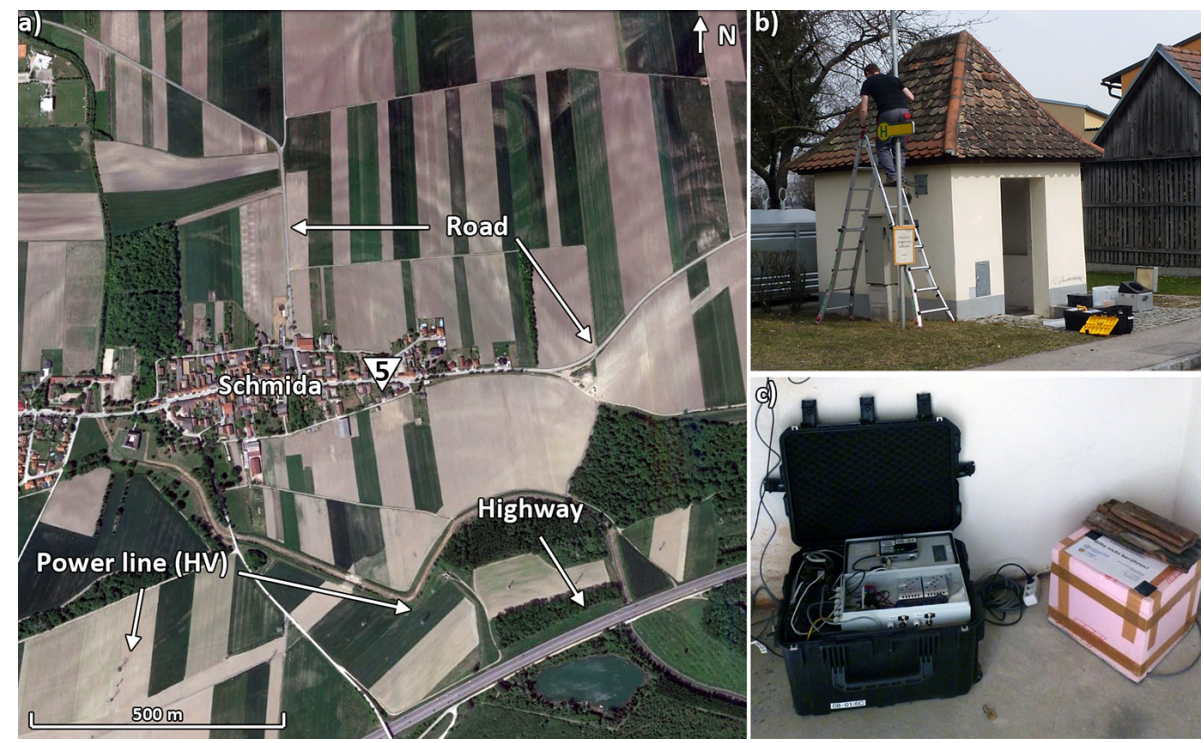

Figure 5. Station 05: (a) aerial view of the surroundings with potential noise sources highlighted, (b) outside view of installation, (c) inside view of installation.
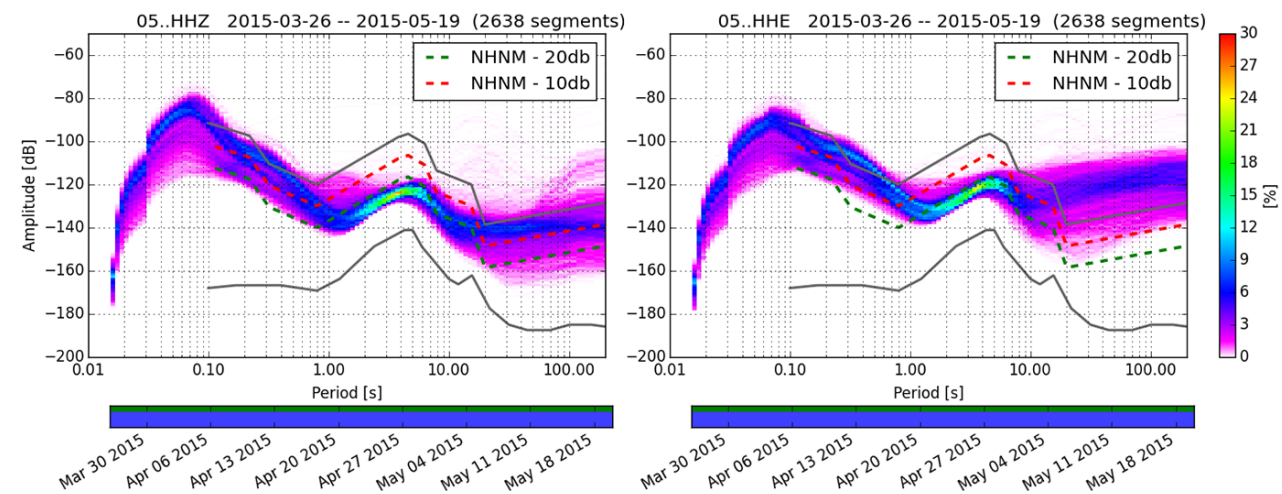

Figure 6. Probabilistic power spectral density of 54 days in spring 2015 of data for Station 05. Left panel: vertical component (HHZ), right panel: horizontal E-W component (HHE).

Following the site requirements listed above, typical installation sites for our broadband instruments are basements in abandoned or occasionally used houses and huts (see Figs. 3-11). In various regions throughout Austria wine cellars and occasionally castles or bunkers may be used for seismic installations. The sensor is placed on solid ground - preferably flat bedrock, but more commonly concrete floors. If no such ground is available, we build a concrete base approximately $15-$ $20 \mathrm{~cm}$ thick and of $60 \times 60 \mathrm{~cm}$ size. The sensors are covered with textile bags fabricated from microfleece material with primaloft insulation (Fig. 2) and styrofoam boxes (Figs. 3-11) for thermal insulation. To minimize air circulation the bottom of the styrofoam boxes is sealed with silicon.

By end of July 2015, 15 temporary stations are running in test operation (Fig. 1). Stations were installed in two phases - five stations were deployed in spring and another ten stations in summer. In the following we compare five of the 15 currently operating sites in detail and discuss noise levels in the light of site surroundings and highlight possible noise sources. We restrict our report to the five sites of the first installation phase since continuous data over more than one week is not available for the stations installed in the second phase. Probabilistic power spectral density graphs were created with the ObsPy toolbox (Krischer et al., 2015) following the procedure of McNamara and Buland (2004). 


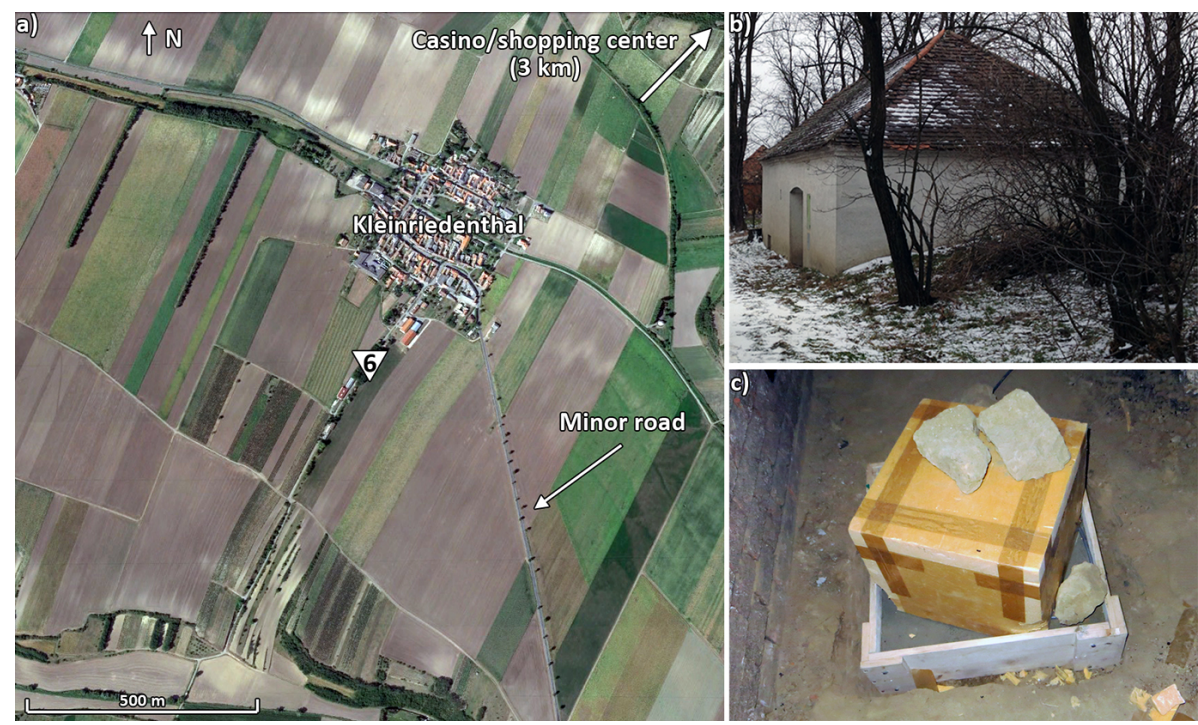

Figure 7. Station 06: (a) aerial view of the surroundings with potential noise sources highlighted, (b) outside view of installation, (c) inside view of installation.
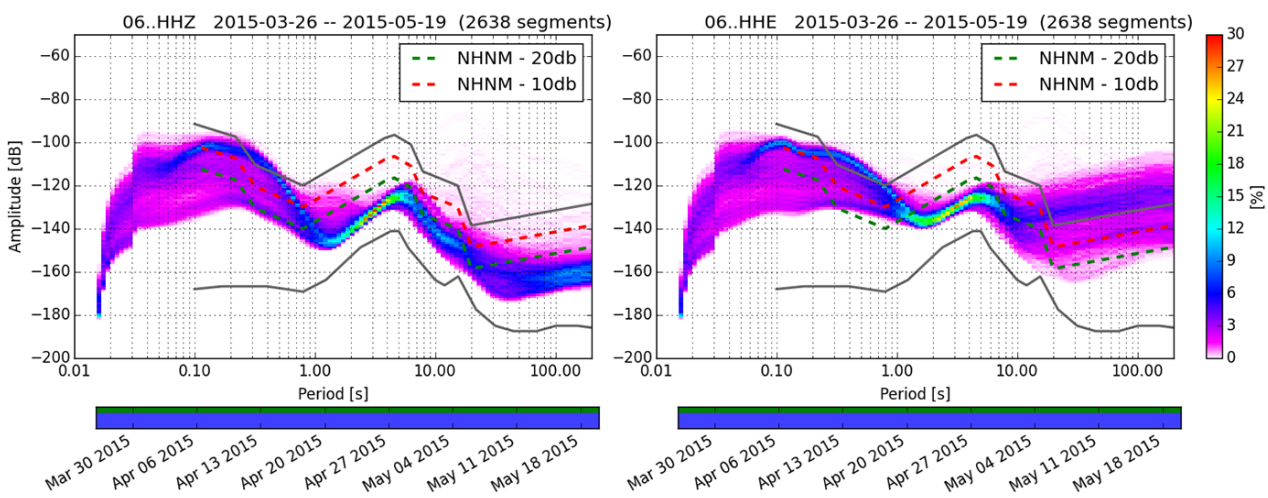

Figure 8. Probabilistic power spectral density of 54 days in spring 2015 of data for Station 06. Left panel: vertical component (HHZ), right panel: horizontal E-W component (HHE).

\section{Site analysis}

\subsection{Site 01}

Station 01 is located in an old bunker near the village of Falkenstein, Lower Austria and power supplied by a solar panel only. It is approximately $600 \mathrm{~m}$ from inhabited houses, $300 \mathrm{~m}$ from a minor road with little traffic and surrounded by vineyards (Fig. 3). The bunker that hosts the seismic station is built upon and likely connected to a $200 \mathrm{~m}$ long outcrop of bedrock which used to be a quarry. Cables for the GPS and mobile antennas are lead to the surface through ventilation pipes, which were sealed with expanding foam. The location inside the bunker provides good ground contact and minimizes daily temperature changes. Consequently, site 01 is by far the most seismically quiet station in the network to date (Fig. 4). Long-period (30-200 s) noise levels on the vertical component are close to the New Low Noise Model (NLNM)
(Peterson, 1993). On the E-W component, long-period noise is substantially higher than on the vertical and approximately $20 \mathrm{~dB}$ less than the NHNM. We note that in the same period range, noise on the $\mathrm{N}-\mathrm{S}$ component is $10 \mathrm{~dB}$ stronger than on the E-W, which may be a sensor leveling effect. The elevated long-period noise on horizontal components compared to the vertical is likely due to ground tilt. In the higher frequencies $(>1 \mathrm{~Hz})$, noise levels are comparable on all components and approximately $10 \mathrm{~dB}$ higher than the NLNM. This shows that anthropogenic noise from the nearby roads and village is small.

\subsection{Site 05}

Station 05 is located in a small stone shelter inside the village Schmida adjacent to the floodplain of the Danube river in Lower Austria (Fig. 5). It is supplied from the power grid. The site is few meters away from a road, $600 \mathrm{~m}$ from a high- 


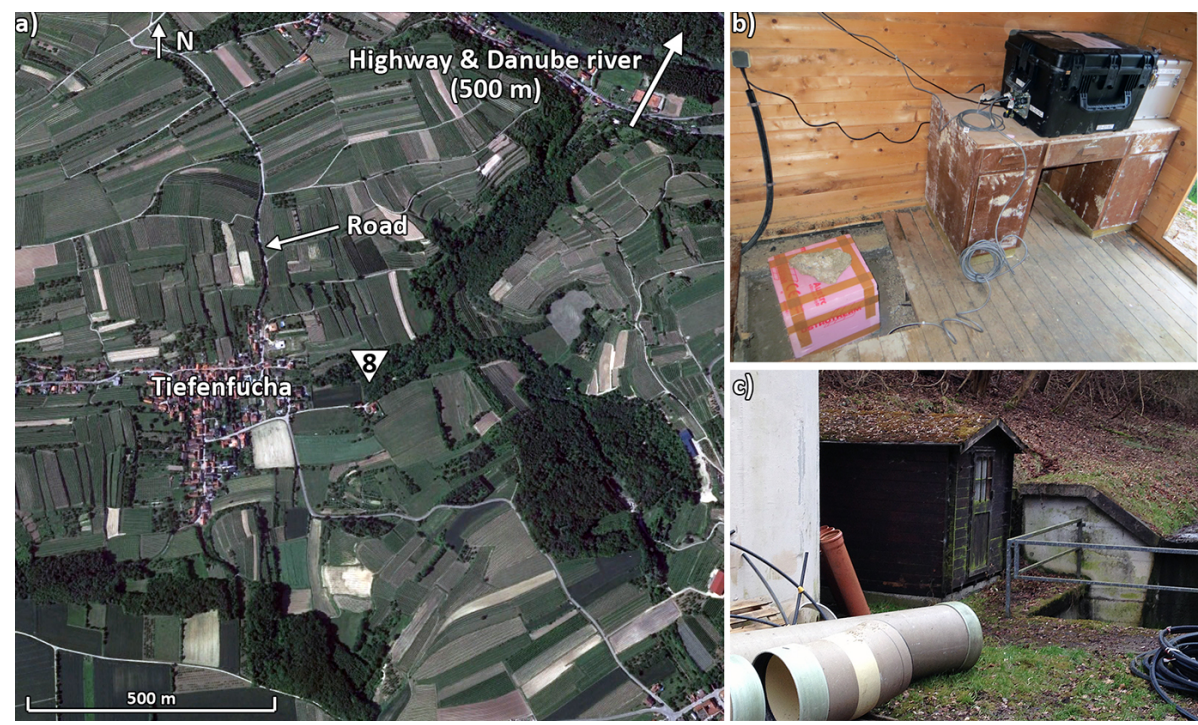

Figure 9. Station 08: (a) aerial view of the surroundings with potential noise sources highlighted, (b) outside view of installation, (c) inside view of installation.
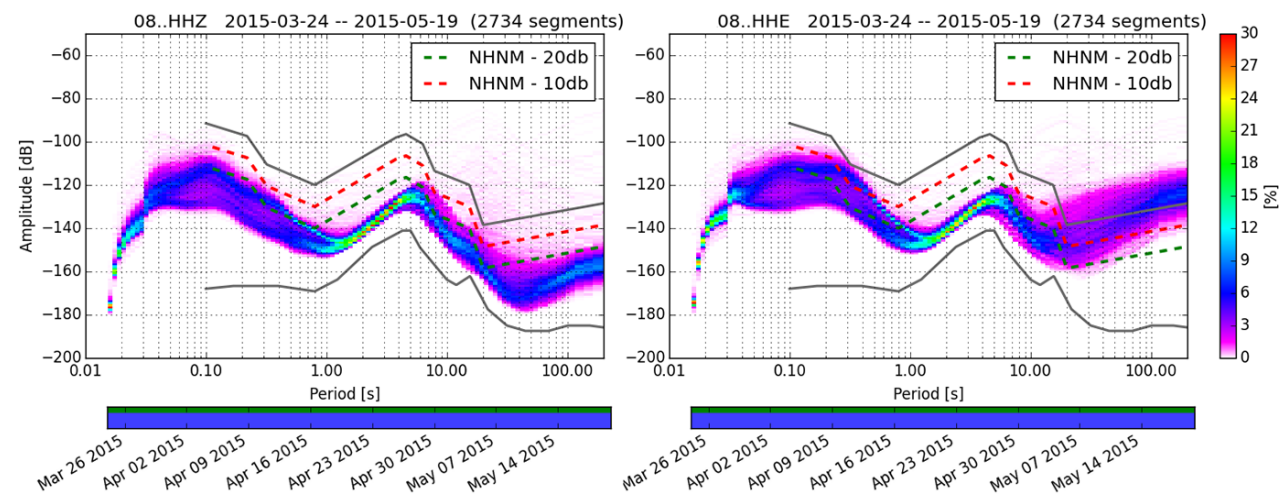

Figure 10. Probabilistic power spectral density of 54 days in spring 2015 of data for Station 08. Left panel: vertical component (HHZ), right panel: horizontal E-W component (HHE).

way and $5 \mathrm{~km}$ from the Danube. The concrete base of the shelter provides good ground contact, yet ground in the entire area is made of loose sediments dominated by the nearby river floodplain. Consequently, noise levels on Station 05 are poor (Fig. 6). Long-period vertical noise levels are in the order of the NHNM while horizontal components suffer from substantially stronger noise. We suspect that the site experiences strong long-period tilt from passing cars. Traffic is most likely also responsible for the elevated high-frequency noise in the order of the NHNM on all three components. In fact, during night times (8:00 p.m. to 6:00 a.m.) noise levels are generally $10 \mathrm{~dB}$ lower on all components than at daytime (6:00 a.m. to 8:00 p.m.) which confirms anthropogenic noise as the main noise source. At night, noise levels on the vertical component are close to NHNM $-20 \mathrm{~dB}$ for both longperiod and high-frequency bands. Despite the generally high noise levels at this site (especially during daytime), record- ings could still be used for identification of both teleseismic and local seismic events (Figs. 13 and 14).

\subsection{Site 06}

Station 06 is placed inside an abandoned wine cellar approximately $5 \mathrm{~m}$ below the surface (Fig. 7) outside the village Kleinriedenthal in Lower Austria. Power supply is from the grid. Since the ground consists of loose soil, we built a concrete base to put the sensor on. The site lies $200 \mathrm{~m}$ outside a small village, $300 \mathrm{~m}$ from a road and is surrounded by vineyard agriculture. Despite the underground location noise levels are high (Fig. 8). Long-period vertical noise is steadily well below NHNM $-20 \mathrm{~dB}$ while horizontal noise levels strongly vary in amplitude and on average fall around the NHNM. This behavior is unexpected since the underground installation should minimize both temperature fluctuations and effects of surface tilt. One reason for the strong 


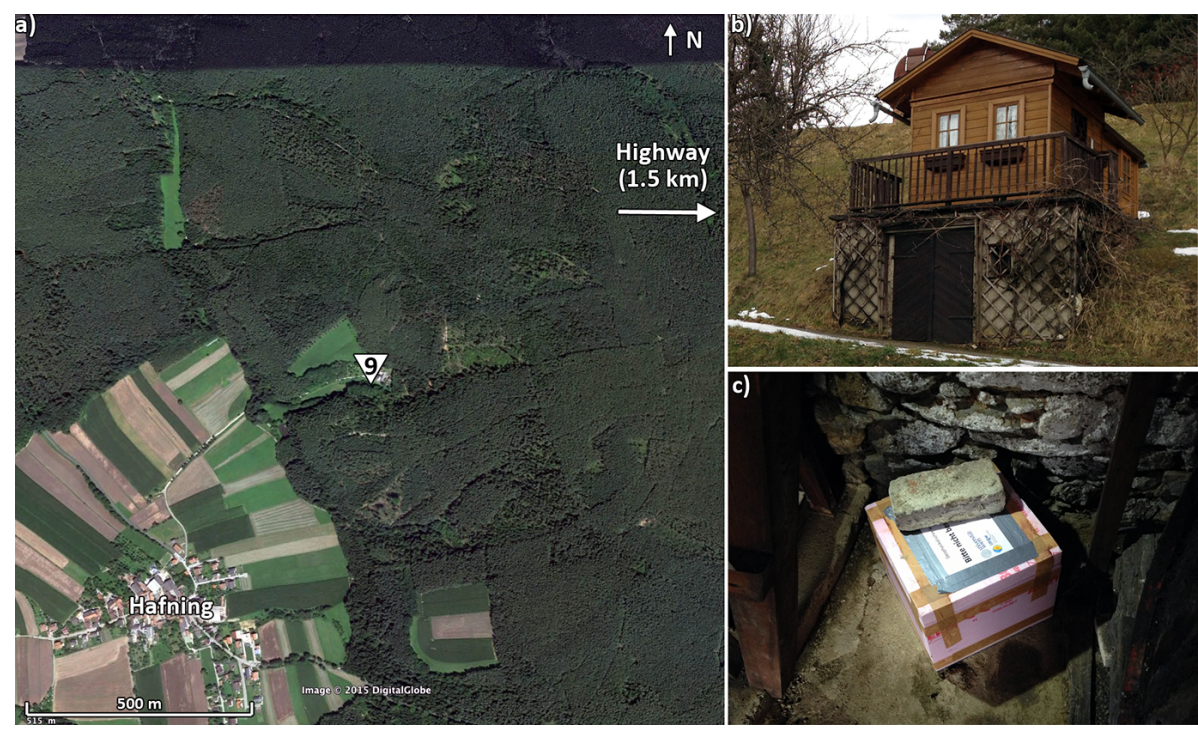

Figure 11. Station 09: (a) aerial view of the surroundings with potential noise sources highlighted, (b) outside view of installation, (c) inside view of installation.
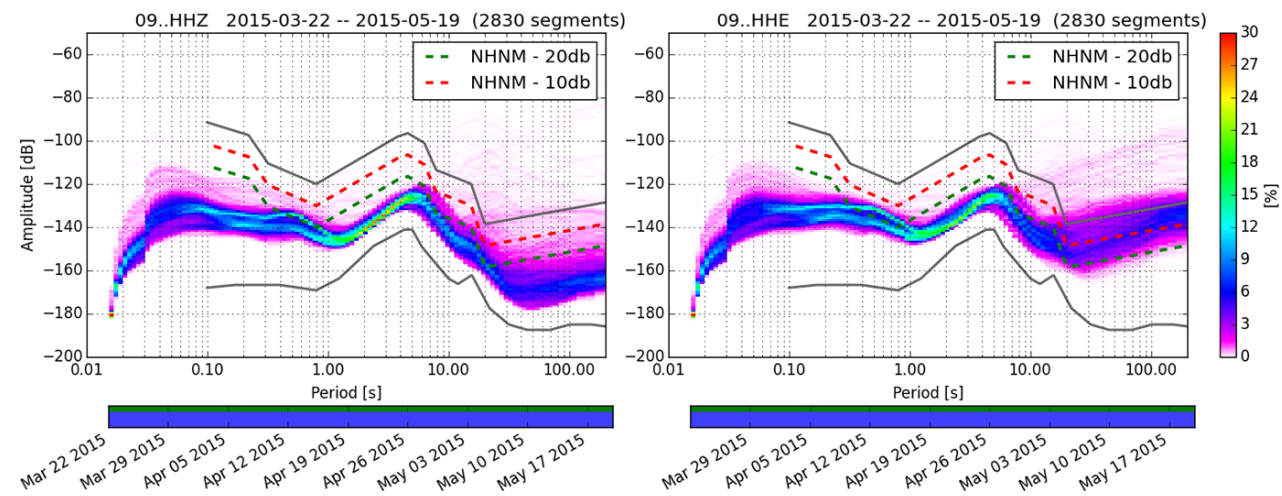

Figure 12. Probabilistic power spectral density of 54 days in spring 2015 of data for Station 09. Left panel: vertical component (HHZ), right panel: horizontal E-W component (HHE).

susceptibility of the horizontal components to long-period noise might be sensor mis-leveling. During its installation the sensor was put on the concrete base which might not have been entirely solid at the time (two days after construction) and thus the sensor or the base may have tilted. Tilted sensors will show much stronger horizontal noise. In fact, upon inspection about 2 months after installation, the sensor leveling did considerably change since the time of installation. The high frequency noise also distributes around the NHNM but also down to $-20 \mathrm{~dB}$ less. The high frequency noise appears to split into a major (close to NHNM) and a minor (close to NHNM $-20 \mathrm{~dB}$ ) branch, which indicates that the elevated noise levels may be due to anthropogenic noise. While we did not expect huge impact of traffic for this site, a comparison of day to night data in fact confirms very clearly that high frequency noise is primarily anthropogenic and as such probably due to traffic. Both on vertical and horizontal components, nighttime noise levels are more than $20 \mathrm{~dB}$ less than during daytime for higher-frequencies and $10 \mathrm{~dB}$ less for longer periods. In addition to traffic from the closest road $(300 \mathrm{~m})$ a huge commercial and recreation facility about $3 \mathrm{~km}$ $\mathrm{NE}$ of the site may contribute to the observed noise levels.

\subsection{Site 08}

Station 08 is placed near a flood protection facility inside a several meter deep artificial trough next to the village Tiefenfucha in Lower Austria (Fig. 9). It is supplied from the power grid. The station is $200 \mathrm{~m}$ from the village, $1.5 \mathrm{~km}$ from a highway and the Danube river and surrounded mostly by vineyards. Trees (approximately $5-10 \mathrm{~m}$ high) surround the site. The sensor is placed atop a base made of concrete which fills the foundation of a small wooden hut, that serves as shelter for the station. An artificial water stream may flow several $\mathrm{m}$ from the station after periods of strong precipita- 


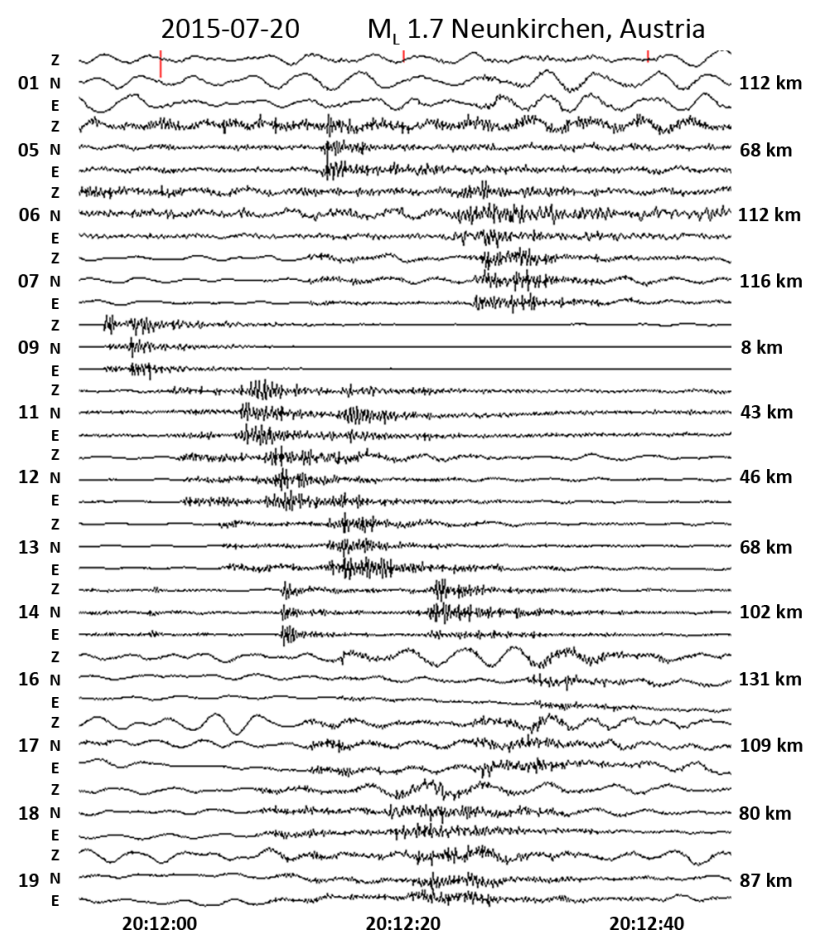

Figure 13. Waveform recordings (unfiltered) of all test sites deployed at the time of a local $M_{1} 1.7$ earthquake near Neunkirchen, Lower Austria. Station 09 is closest to the epicenter. Note, that even on very noise sites such as 05 (68 km distance) and 06 (112 km distance) $\mathrm{S}$ wave arrivals can be recognized. Without filtering, the signal on the $112 \mathrm{~km}$ distant bunker site 01 is dominated by microseism noise. The earthquake signal can be recovered on all 13 stations operative at the time. For most stations both $P$ and $S$ arrivals could be picked.

tion but is almost non-existing during dry conditions. Longperiod noise levels (Fig. 10) are well below NHNM $-20 \mathrm{~dB}$ on the vertical component but significantly higher on horizontal components. High-frequency noise splits into two branches on all three components which likely reflects the effect of day and night anthropogenic noise or workday to weekend variations. Despite the comparably small distance between the station and the closest houses, high-frequency noise levels are reasonably well below NHNM $-10 \mathrm{~dB}$ or even NHNM $-20 \mathrm{~dB}$.

\subsection{Site 09}

Station 09 is located inside a rarely used storage cellar that is built into the slope of a hill (Fig. 11) and supplied from the power grid. The site is close to a secluded family house and $800 \mathrm{~m}$ from any larger settlement (Hafning, Lower Austria), $1.5 \mathrm{~km}$ from a highway and mainly surrounded by forest. The installation inside the cellar reduces surface effects which results in low long-period noise levels (Fig. 12). While the vertical component long-period noise level is approximately only $10 \mathrm{~dB}$ higher than the NLNM, horizontal noise-

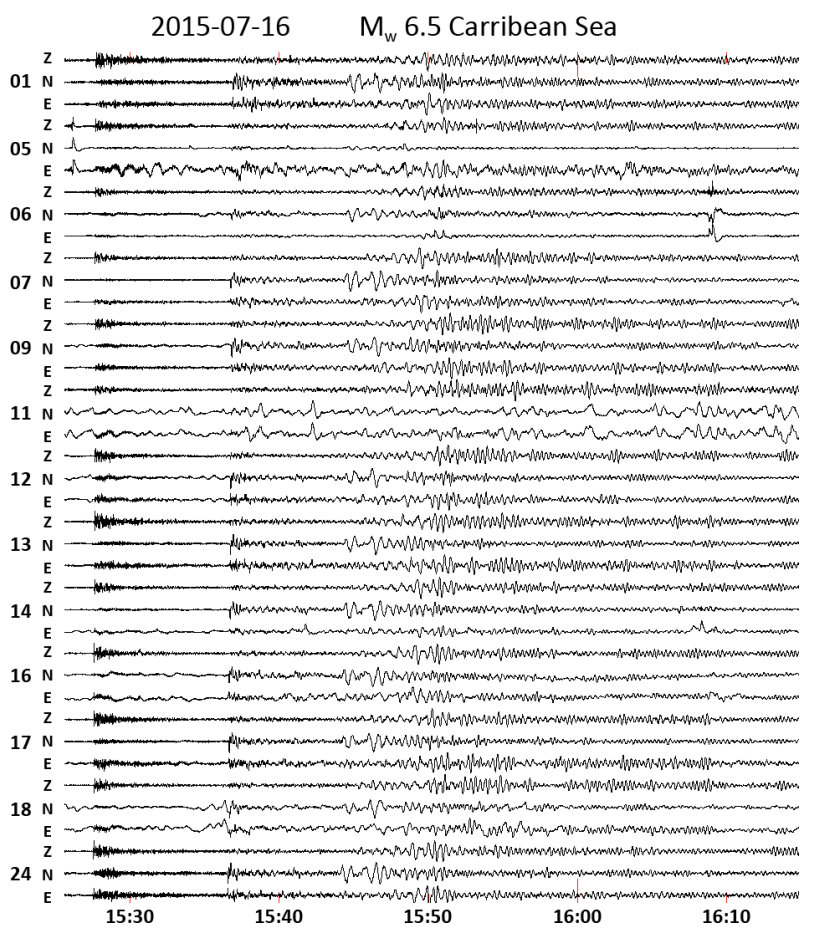

Figure 14. Waveform recordings (unfiltered) of all test sites deployed at the time of a teleseismic $M_{\mathrm{W}} 6.5$ earthquake in the Caribbean Sea approximately $7700 \mathrm{~km}$ from the network. Multiple phase arrivals and clear surface waves can be identified on all stations operative at the time.

levels fall around NHNM $-10 \mathrm{~dB}$ but are still within the desired range. High-frequency noise on all components separates into two branches which, however, fall below NHNM $-20 \mathrm{~dB}$. This likely reflects the little anthropogenic noise originating from the nearby house. Among the sites where continuous data is available for more than one week, Site 09 performs second best to the installation inside the bunker (Site 01).

\section{Network performance and first selected seismic events}

Several of the sites discussed above experience substantially higher long-period noise levels on the horizontal components than on the vertical components. Yet, most of the sites show comparably low long-period noise levels on the vertical component, in the range of $20 \mathrm{~dB}$ lower than the NHNM. With one exception (wine cellar) all of our sites are surface or nearsurface installations and we did not attempt for sophisticated protection against pressure variations and surface tilt such as pressure sealed sensor covers or very stiff gabbro baseplates (Forbinger, 2012). Consequently, elevated long-period noise on the horizontal components due to local surface tilt induced by pressure gradients (Bormann and Wielandt, 2012) is expected and unavoidable for the type of installation described 
here. Still, because of the additionally strong noise in higherfrequency bands, stations 05 and 06 may be relocated for the final deployment within the AlpArray framework.

Except for the sites discussed above, most of the preliminary stations by end of July 2015 were only running for less than seven days with telemetry data. Hence, we did not attempt to analyze noise levels for these stations. However, we can still get a first impression of the site qualities by checking the waveform data of earthquakes that have been recorded by the network. As examples we show here the unfiltered recordings (not corrected for instrument response, all sensors are of similar specifications) of a local $M_{1} 1.7$ earthquake near Neunkirchen, Lower Austria (Fig. 13) and a teleseismic event (Fig. 14) with $M_{\mathrm{w}} 6.5$ at approximately $7700 \mathrm{~km}$ distance in the Caribbean Sea. Note, that the local event occurred during potentially more quiet evening times, while the teleseismic event was recorded during more noisy mid-day time. However, long-period teleseismic signals are not strongly affected by anthropogenic high-frequency noise. Both events can be well recognized on all stations even on unfiltered waveform data. Several seismic phases may be identified on closer inspection. Thus, almost all preliminary stations perform reasonably well and meet the multipurpose requirements of capturing both local and distant seismic events that will allow for various geodynamical studies.

\section{Conclusions}

In the framework of the upcoming AlpArray project we described our preparations for temporary seismic broadband installations in Austria. Following the specific project requirement (stations should perform reasonably well in the two frequency bands $1-20 \mathrm{~Hz}$ and $30-200 \mathrm{~s}$ ) a typical installation comprises microfleece and styrofoam covered sensors in the basements of unutilized houses or huts. One station is located inside an abandoned bunker. By the end of July 2015, 15 stations are in testing operation, five of which are operating since spring 2015. For these five we presented probabilistic power spectral densities that allow for a first noise characterization of the sites. While generally most stations perform reasonably well in a range of NHNM $-10 \mathrm{~dB}$ to NHNM $-20 \mathrm{~dB}$ on the vertical component, the bunker station is exceptionally quiet and two of the three stations near or inside villages suffer from elevated anthopogenic noise and are thus considered for replacement. Since most of our sites are surface or near surface installations, horizontal noise levels are generally higher by approximately $10-20 \mathrm{~dB}$ than the vertical. Still, first events recorded with the complete set of 15 test sites are well resolved on all stations which indicates that following the site selection and preparation that we describe in this manuscript can result in seismic stations that perform reasonably well for both local and teleseismic events.

\section{Data availability}

Seismic data used for this manuscript is not publicly accessible by decision of the AlpArray working group. Waveform data from the preliminary station tests may be available upon request directed to the corresponding author of this manuscript (florian.fuchs@univie.ac.at).

Acknowledgements. AlpArray Austria is funded by the FWF Austrian Science Fund project number P 26391. We acknowledge planning and organization of the AlpArray coordinators Edi Kissling, György Hetenyi, Irene Molinari and John Clinton at ETH Zürich, Switzerland, who created the AlpArray seismic network layout. We thank Johann Huber for technical assistance and Dimitri Zigone for help in the field. We thank all involved Austrian communities, forest administrations and individuals for their help during site scouting. We thank Aladino Govoni and an anonymous reviewer for their suggestions to improve the manuscript.

Edited by: D. Pesaresi

Reviewed by: A. Govoni and one anonymous referee

\section{References}

Bormann, P. and Wielandt, E.: Seismic Signals and Noise, in: New Manual of Seismological Observatory Practice 2 (NMSOP2), edited by: Bormann, P., Deutsches GeoForschungsZentrum GFZ, Potsdam, Germany, 1-62, doi:10.2312/GFZ.NMSOP2_ch4, 2012.

Forbinger, T.: Recommendations for seismometer deployment and shielding, in: New Manual of Seismological Observatory Practice 2 (NMSOP-2), edited by: Bormann, P., Deutsches GeoForschungsZentrum GFZ, Potsdam, Germany, 110, doi:10.2312/GFZ.NMSOP-2_IS_5.4, 2012.

Kissling, E., Hetenyi, G., and AlpArray Working Group: AlpArray - Probing Alpine geodynamics with the next generation of geophysical experiments and techniques, Geophysical Research Abstracts, EGU General Assembly 2014, Vienna, Austria, 16, EGU2014-7065, 2014.

Krischer, L., Megies, T., Barsch, R., Beyreuther, M., Lecocq, T., Caudron, C., and Wassermann, J.: ObsPy: a bridge for seismology into the scientific Python ecosystem, Computational Science \& Discovery, 8, 014003, doi:10.1088/1749-4699/8/1/014003, 2015.

McNamara, D. E. and Buland, R. P.: Ambient noise levels in the continental United States, B. Seismol. Soc. Am., 94, 1517-1527, doi:10.1785/012003001, 2004.

Peterson, J.: Observations and modeling of seismic background noise, USGS Open-File report, 93-322, 1993.

Trnkoczy, A., Bormann, P., Hanka, W., Holcomb, L. G., Nigbor, R. L., Shinohara, M., Shiobara, H., and Suyehiro, K.: Site Selection, Preparation and Installation of Seismic Stations, in: New Manual of Seismological Observatory Practice 2 (NMSOP-2), edited by: Bormann, P., Deutsches GeoForschungsZentrum GFZ, Potsdam, Germany, 1-139, doi:10.2312/GFZ.NMSOP-2_ch7, 2012. 